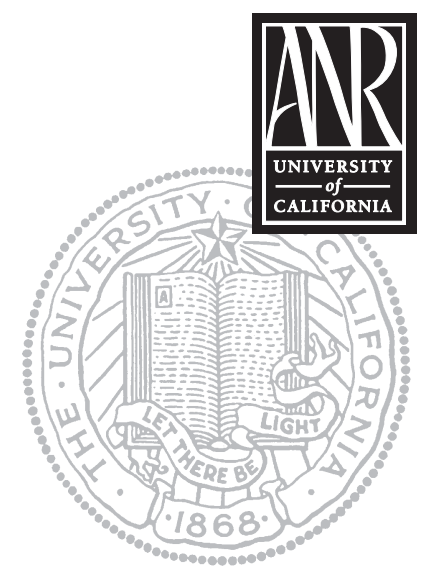

UNIVERSITY OF CALIFORNIA

Division of Agriculture and Natural Resources http://anrcatalog.ucdavis.edu

CHUCK INGELS, University of California Cooperative Extension Farm Advisor, Environmental Horticulture, Sacramento County; PAMELA M. GEISEL, University of California Cooperative Extension Farm Advisor, Environmental Horticulture, Fresno County; CAROLYN L. UNRUH, University of California Cooperative Extension staff writer

\title{
Fruit Trees: Training and Pruning Deciduous Trees
}

There are many ways to train and prune deciduous fruit trees, and no single method is right for all situations and needs. When selecting fruit trees, one important consideration is the desired size of the trees at maturity. Many people prefer small (dwarf and semidwarf) trees because they are easier to manage and harvest and because more trees can be grown in a limited space. Other people prefer full-sized trees because they provide more shade and more fruit per unit area.

\section{GENETIC DWARF TREES}

Genetic dwarf trees usually produce very short internodes (the space on a shoot between two leaves), resulting in compact branches with dense foliage. These trees grow to about 8 to 10 feet $(2.4$ to $3.0 \mathrm{~m})$ tall and wide at maturity. They make beautiful landscape trees that are easily managed to provide adequate amounts of fruit for a single family. Excellent varieties are available in peaches, nectarines, and apples. The lower and interior fruiting branches of genetic dwarf trees, especially peaches and nectarines, tend to die quickly due to shading by the dense growth. However, the trees are small, so production of fruit on the extremities of the higher branches is not a serious problem as long as the branches are strong enough to hold the weight of the fruit.

Pruning genetic dwarf trees mainly involves thinning the branches in the dormant season to open up the canopy and maintain the height and spread of the tree. Control tree size and strengthen limbs by removing branches at their point of attachment to the trunk or a larger branch (thinning cuts), rather than by heading or "topping" them. For definitions of pruning terms, refer to the glossary.

\section{FULL-SIZED AND SEMIDWARF TREES}

Full-sized trees on standard rootstocks can grow to 25 to 30 feet ( 7.6 to $9.1 \mathrm{~m}$ ) tall, while trees on semidwarfing rootstock can reach 15 to 20 feet $(4.6$ to $6.1 \mathrm{~m})$ tall. Both standard and semidwarf trees can be kept relatively small by pruning, but trees of this size may still grow too large for many backyard situations. An excellent selection of truly dwarfing apple rootstocks is usually available, and truly dwarfing rootstocks are being developed for most fruit species. Depending on the type of tree (growth habit and location of fruiting buds), full-sized and semidwarf trees may be trained to an open center, central leader, or fruit bush system.

\section{Open Center System}

The open center, or vase-shaped, system (fig. 1) is most commonly used on almond, apricot, cherry, fig, nectarine, peach, plum, and prune trees. Many pear, apple, and pistachio trees are also trained to this system. With this method, the center of the tree is kept free of large branches and vigorous upright shoots (suckers and watersprouts) in order to allow sunlight to reach the lower fruiting wood.

First growing season. To create an open center tree, in about late April of the first growing season select three or four shoots that will become the primary scaffold branches (main structural branches) and pinch back all other strong upright shoots to 4 to 6 inches 


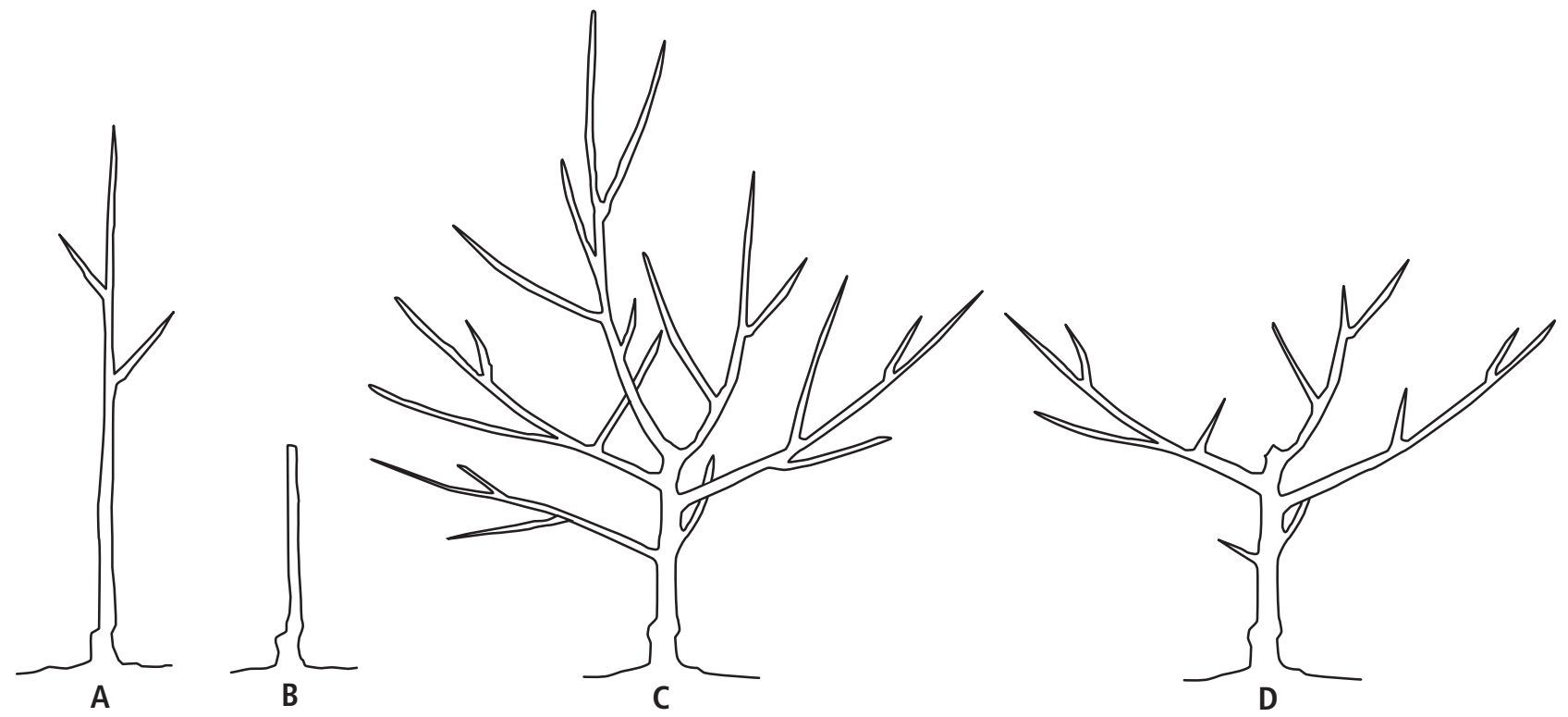

Figure 1. Open center pruning method. (A) Bare root tree at planting time. (B) Tree headed after planting. (C) Growth after one season. (D) Tree pruned after one growing season.

(10 to $15 \mathrm{~cm}$ ) long. When possible, these scaffold branches should be spaced several inches apart vertically and should be distributed evenly around the trunk, with the lowest branch about 18 to 24 inches $(46$ to $60 \mathrm{~cm}$ ) above the ground. If growth is vigorous, the selected scaffold branches should be pinched back or headed to about 2 to $2 \frac{1}{2}$ feet (60 to $75 \mathrm{~cm}$ ) long in late May or early June (or when growth is long enough) to promote side branching and the development of secondary scaffold branches. Continue to pinch or head back unwanted branches but leave lateral shoots for next year's fruit production. These unwanted branches will be removed later, but they provide shade for the trunk and main branches of young trees during the current growing season. If summer pruning was not done or was insufficient, create the open center during the dormant season. Continue to develop secondary scaffold branches in subsequent growing seasons.

First dormant season after planting. Select three or four primary scaffold branches if this was not done the previous summer. Do not select scaffold limbs that grow directly above one another. Avoid upright limbs that are attached with narrow, acute angles because they tend to be weak at the point of attachment. Flat or horizontal limbs should be avoided as scaffold limbs, but they can be used if new shoots coming from them are directed upward and outward. For most species, a $45^{\circ}$ angle for limb attachment is most desirable. If the tree grows poorly the first year, severely head back the primary scaffolds to three or four buds to promote vigorous growth the next year and correct the causes of the poor growth.

Cherry, plum, and pear trees produce very upright growth. To promote tree spread, the scaffolds should be bent outward while still flexible or cut back to outside lateral branches. Other trees, such as apricots, peaches, and almonds, have a spreading growth habit and tend to produce lateral branches without heading. With these varieties it is often necessary to remove flatter-angled branches and leave more upright branches, thus maintaining the upward, outward growth pattern.

Developing the mature tree. Heading or pinching the primary scaffold branches encourages secondary scaffold branches to grow from them. Allow two to three secondary branches to develop from each primary. Remove all other strong branches, preferably during the summer, to reduce competition with the scaffold branches and provide 
sunlight to lateral fruiting branches and spurs. Head or pinch the secondary scaffold branches at 2 to $2 \frac{1}{2} 2$ feet ( 60 to $75 \mathrm{~cm}$ ) long to develop two to three "tertiary" branches from each secondary branch. Ideally, two branches should originate from each primary and secondary, and they should grow upward and outward but away from each other. However, shoot growth seldom conforms to this structure.

Mature trees. Pruning mature open center fruit trees involves keeping the center free of vigorous upright shoots, reducing tree height, and thinning out branches to reduce crowding. For peaches and nectarines, select 1-year-old lateral fruiting branches that originate close to main branches. Thin these fruiting branches (one-third to one-half of them can be removed) and head them by one-third if they are longer than about 1 to 2 feet $(30$ to $60 \mathrm{~cm}$ ). Remove or cut back 2-year-old fruiting shoots or cut them back to 1year-old shoots. On other species, old fruiting spurs should be renewed periodically. Table 1 shows the location of fruiting buds, the longevity of spurs, and the desired severity of pruning of selected species. When dormant pruning, become familiar with the plump fruiting buds and prune accordingly to ensure adequate flowering the following spring. Pruning of mature almonds involves few or no heading cuts; simply thin out branches-often fairly large branches—to prevent crowding.

\section{Central Leader System}

Central leader training (fig. 2) is often used for apples and sometimes for pears, Asian pears, pecans, and quince. These trees tend to have dominant central leaders, a character-

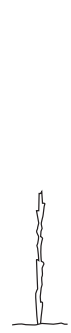

A

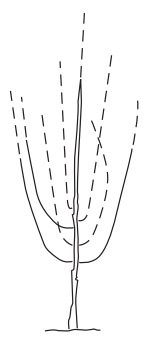

B
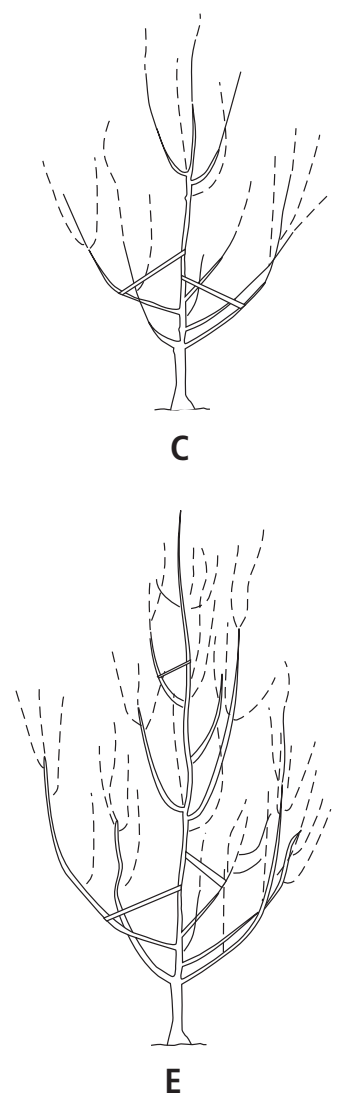

Figure 2. Central leader pruning method. (A) Bare root tree at planting time. (B) First tier of scaffold branches and reestablished central leader. (C) First tier of branches staked into desired position as second tier of branches is established. Branches developed in the third (D) and subsequent (E) years are spaced evenly around and up the central leader. Note the $45^{\circ}$ angle of branch attachment formed by using spreading bars. istic that lends itself to the central leader training method. However, because many apple and pear varieties are susceptible to fire blight, open center or other multiple-leader methods are often preferred so that if a major limb is lost the tree can be more easily redeveloped. Central leader training involves keeping trees shaped somewhat like Christmas trees, with lateral branches arranged in separate layers, or "tiers," separated by open areas of canopy, and branches in lower tiers wider than those in upper ones. Instead of sunlight reaching lower fruiting branches through the center, as with the open center method, it reaches them from the sides and between branches.

For young central leader trees, the goal is to create three or four tiers of lateral branches, with about four branches per tier. This is done preferably during spring and summer by heading back (and later removing) or bending down any vigorous shoots that grow upright and compete with the central leader. Create the first tier of four lateral branches by tying or staking branches outward at an angle just above horizontal after they have grown 2 to 3 feet $(60$ to $90 \mathrm{~cm}$ ) long. When the central leader has reached about $2 \frac{1}{2}$ to 3 feet $(75$ to $90 \mathrm{~cm})$ past the first tier, usually in the first dormant season after planting, head it just below this point and train a second tier of four branches outward from the cut leader. These branches should be offset vertically from those of the first tier. Allow the most vigorous upright shoot to continue its growth as the central leader. Then create the third tier in a similar manner. Avoid bending one branch directly over anoth- 
Table 1. Fruiting wood characteristics and pruning of fruit trees

\section{Location of fruiting buds}

\section{On long shoots}

Type of tree
almond
apple

apricot

cherry, sweet

fig

nectarine

peach

pear, Asian

pear, European

persimmon

plum, European

plum, Japanese

quince

walnut

minor

\section{minor}

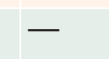

$-$

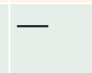

major

$$
\text { major }
$$
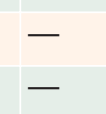

$$
\text { major }
$$

minor

minor

major

minor

very minor

minor

major
On short shoot or spurs

\begin{tabular}{l|l} 
Laterally & Terminally \\
minor & -
\end{tabular}

very minor

very minor

Laterally
major

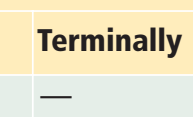

- major

$\begin{array}{ll}\text { major } & - \\ \text { major } & - \\ - & -\end{array}$

very minor

minor on young

trees

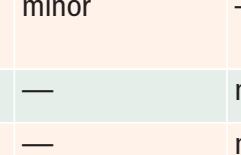

minor

trees
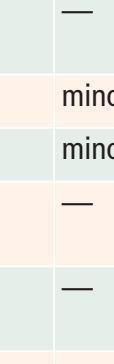

minor
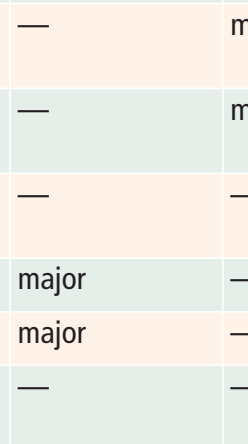

minor on

\begin{tabular}{|c|c|c|}
\hline $\begin{array}{l}\text { Spur life } \\
\text { (years) }\end{array}$ & $\begin{array}{l}\text { Type of training } \\
\text { system }\end{array}$ & $\begin{array}{l}\text { Amount of } \\
\text { pruning for } \\
\text { mature trees }\end{array}$ \\
\hline 5 & open center & light (thinning) \\
\hline $8-10+$ & $\begin{array}{l}\text { central leader, open center, } \\
\text { or modified central leader }\end{array}$ & medium \\
\hline 3 & open center & heavy \\
\hline $10-12$ & open center & light \\
\hline $\begin{array}{l}\text { bears on 1-yr and } \\
\text { new shoots }\end{array}$ & $\begin{array}{l}\text { open center or modified } \\
\text { central leader }\end{array}$ & various \\
\hline $1-2$ & open center & heavy \\
\hline $1-2$ & open center & heavy \\
\hline $6-8$ & $\begin{array}{l}\text { central leader or open } \\
\text { center }\end{array}$ & medium to heavy \\
\hline $8-10$ & $\begin{array}{l}\text { central leader or multiple } \\
\text { leader }\end{array}$ & medium \\
\hline $\begin{array}{l}\text { bears on new } \\
\text { shoots }\end{array}$ & modified central leader & $\begin{array}{l}\text { light (mainly } \\
\text { thinning) }\end{array}$ \\
\hline $6-8+$ & open center & medium \\
\hline $6-8$ & open center & heavy \\
\hline $\begin{array}{l}\text { bears on new } \\
\text { shoots }\end{array}$ & $\begin{array}{l}\text { central leader or open } \\
\text { center }\end{array}$ & $\begin{array}{l}\text { light (mainly } \\
\text { thinning) }\end{array}$ \\
\hline 8-10 & modified central leader & light (thinning) \\
\hline
\end{tabular}

mature trees

er; also, maintain the tree's pyramidal shape by keeping lower branches longer than upper branches. The entire process will take 3 to 4 years, depending on the tree's vigor.

Some side branching of these main lateral branches should be encouraged. Vigorous upright shoots should be removed or headed back during the growing season to only three to six buds, although some shoots should be left longer if fruit are exposed to hot afternoon sun. Heading these shoots a couple of times during the growing season creates fruit-bearing spurs if the tree is not too vigorous. Heading may also encourage the growth of another set of vigorous shoots; simply remove these shoots or prune them back to create more spurs.

\section{Modified Central Leader System}

In commercial orchards, walnuts and persimmons are typically trained using the modified central leader system. With this method, young trees are pruned and trained as in the central leader system, but after several main lateral branches are developed, the central leader is removed. For this reason, it is also referred to as a delayed open center system.

Like the central leader system, the most upright vigorous shoot is developed into the leader, and other branches are headed back except for two or three lateral branches that are well spaced both around the tree and vertically, rather than in distinct tiers. A total of about five to seven such branches can be developed, after which the central leader is removed, or the top two or three branches simply become codominant. These main branches must be offset from each other, with no limb directly over another limb, in order to keep the limb strong and sunlit. 
With walnuts, the first main branch originates higher than on most trees, about 5 to 8 feet ( 1.5 to $2.4 \mathrm{~m}$ ), and the spacing between branches is about 3 to 5 feet ( 0.9 to 1.5 $\mathrm{m})$. Pruning of mature walnut trees is not essential, but thinning of branches will keep trees healthy and productive.

Persimmons bear on current-season shoots that originate from buds produced near the ends of 1-year-old lateral branches. For this reason, once the tree is developed, avoid heading these shoots and be sure that sunlight reaches lower shoots, or they will become less productive or die. Also, each limb must be kept strong from the start by ensuring adequate sunlight and shortening branches if necessary by cutting back to upward- and outward-growing lateral branches. Avoid heading cuts except to stimulate branching, such as on young trees; such heading cuts are best made in late spring and summer to reduce strong upright growth of "whip" branches. Persimmons often grow taller than is desired for picking fruit. Trees that are allowed to grow unchecked can make large, beautiful trees; however, branches often break with the weight of fruit. If they are headed at a given height each year, the subsequent vigorous shoots will shade lower shoots by midsummer, so these shoots must be thinned by summer pruning. Where possible, cut to lateral branches rather than making heading cuts.

\section{Fruit Bush System}

"Fruit bushes" (fig. 3) are standard (full-sized) trees or, preferably, trees on dwarfing rootstock that are kept small by periodic summer pruning. This method can work for nearly all fruit species. The beauty of this system is its simplicity and ease of management. Pruning begins in about late April or early May of the first growing season, when new growth is about 2 feet $(60 \mathrm{~cm})$ long. At this time, cut the new growth in half, aiming for a uniform, bushy appearance. Hedge-trimming shears may be useful in this. In about late June, cut the subsequent new growth in half. If new growth is vigorous, it may need to be cut once more during the season. These heading cuts promote an excess of branches, so thin them by removing some shoots to allow sunlight to reach the lower branches. If needed, thin out additional crowding branches in the dormant season when they are more visible.

In the second year, continue cutting new growth in this manner until the trees reach 5 to 7 feet $(1.5$ to $2.1 \mathrm{~m}$ ) tall, a height at which you can easily prune the top. Pruning in subsequent years involves cutting off any shoots above the tree's permanent

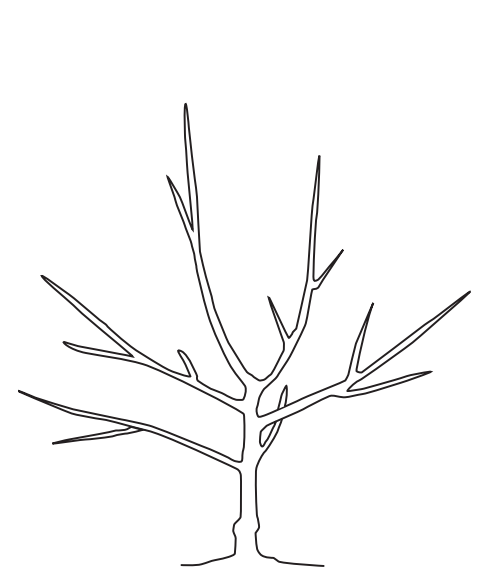

A

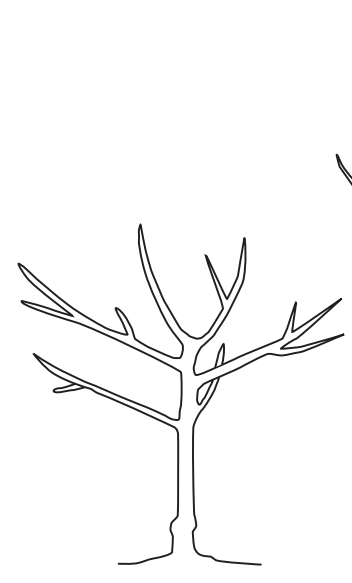

B

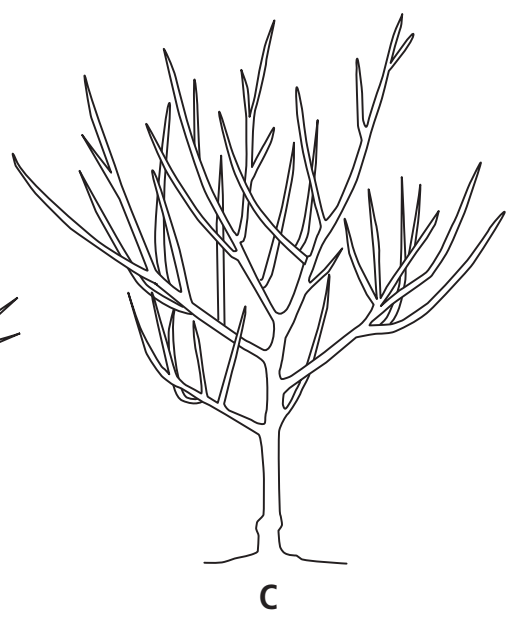

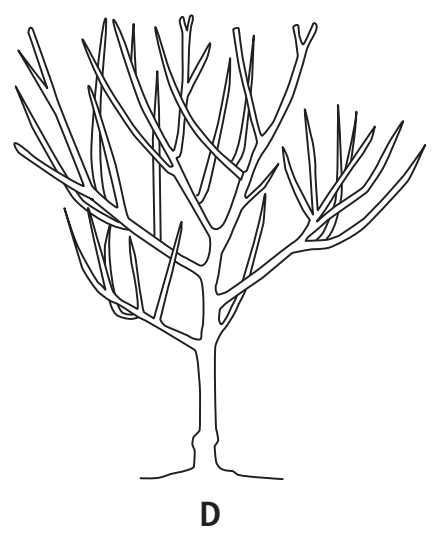

D

Figure 3. Fruit bush pruning method (leaves removed to show structure). (A) New growth early in the first growing season (late April to early May). (B) Initial heading of new growth. (C) Subsequent new growth following heading (June). (D) Additional growth headed back. Vigorous trees may require pruning one or two more times during the first growing season. Continue heading back each year until the tree reaches the desired height. 
height two to three times per year. Also, thin crowding branches, especially at the top of the tree, and remove unproductive fruiting wood in early spring when branches without flowers are visible.

\section{SUMMER VERSUS DORMANT PRUNING}

No matter which training method you choose, do some pruning in the spring and summer to train young trees and shorten the time to full fruit production. When necessary, bend and stake shoots of young trees during the spring and summer so they will grow in the desired direction. Bending branches in this manner develops the scaffold structure faster than heading them and waiting for new lateral branches to form. On mature trees, summer pruning mainly involves removing vigorous upright shoots that are not needed as permanent branches and heading or thinning shoots to control tree height and develop branches.

If trees receive appropriate summer training and pruning, far less dormant pruning is necessary. However, the absence of leaves in winter provides a clear view of the framework of the tree. At that time, thin or head any branches that were not adequately pruned during the growing season.

One notable feature about apricots is that they are susceptible to infection by the branch-killing disease eutypa dieback, which is a particularly serious problem in Northern California around the San Francisco Bay Area. Infection occurs on wounds made in fall or early winter, causing severe gumming at pruning wounds and branch dieback. Therefore, it is best to prune apricots either in late summer, so that at least 6 weeks of rain-free weather follow the pruning, or late in the dormant season (late winter), by which time far fewer viable spores are present. If pruned in summer, be sure to prevent sunburn by leaving enough foliage to cover limbs or by painting exposed limbs white with a 50-50 mixture of interior white latex paint and water.

\section{MAKING PRUNING CUTS}

Use pruning shears to cut small branches and shoots. There are two types of pruning shears: bypass (two blades pass each other, like scissors) and anvil (one blade cuts down against a flat surface). Bypass shears are somewhat better for cutting very small shoots; anvil shears tend to work better on larger shoots or branches. Use a sharp pruning saw for branches too large to be cut with anvil shears. Keep pruning tools sharp: dull tools make rough cuts, which can promote insect damage or disease.

Make pruning cuts at a $45^{\circ}$ angle across the branch. To prevent water from ponding on the cut, the cut surface should angle downward and away from horizontal. Make thinning cuts just beyond the branch collar (the slightly raised area on the main branch at the point of attachment of the branch to be cut). Do not cut into the branch collar. Cut large limbs or branches in a two-step process: first cut off the limb about two feet from its point of attachment, then make the final cut just beyond the branch collar. When making the first cut, make a small cut on the underside of the branch to keep the stub from splitting.

Do not apply emulsions, paint, or other materials to pruning cuts. Leave the cuts open to the air, so they can dry out and heal naturally. Emulsions and other materials can trap moisture and lead to disease.

For more information on making pruning cuts, see the California Master Gardener Handbook (ANR Publication 3382, 2002) pp. 322 and 489. 


\section{GLOSSARY OF PRUNING TERMS}

bare root. Nursery stock in which the plant is sold without soil around the roots. canopy. The part of the tree composed of leaves and small twigs.

central leader. The main trunk of the tree; a method of training trees that consists of a single dominant trunk and tiers of lateral branches.

crown. The aboveground parts of the tree, including the trunk. The root crown is the trunk below ground and the large roots coming from the trunk.

dormant pruning. Pruning that takes place when the tree is not actively growing, such as in winter for apple trees.

heading cut. Removing a portion of a shoot or branch, leaving only buds or a tiny twig on the remaining portion; results in an increased number of branches. Compare with thinning cut and topping.

internode. The part of a stem between two nodes.

latent bud. A dormant bud that is more than 2 years old but has grown enough each year so that its growing point remains at or near the surface of the bark.

lateral. A secondary branch arising from scaffold limbs.

leader. A dominant upright branch. The central leader is the trunk that extends from the root to the top of a tree.

open center. A method of training trees in which scaffold branches are trained upward and outward from the trunk and the center is kept free of vigorous upright shoots.

primary scaffold limb. One of the major limbs arising from a tree trunk.

rootstock. The plant that provides the root system upon which the desired fruiting variety has been budded or grafted.

scaffold. Main branch that forms the structure of an open center tree.

shoot. The growth that emerged from a bud in the current growing season.

spur. Short twig that is specialized for bearing flower buds and fruit on many fruit species.

sucker. Vigorous upright shoot that arises below the bud union from the rootstock or roots.

thinning cut. Removing branches at their point of origin or to a lateral whose diameter is at least 50 percent larger than the diameter of the removed branch. Thinning results in a reduced number of branches. Compare with heading cut.

tier. Arrangement of three or more buds or branches at the same level around the stem.

topping. Reducing the height of a tree by heading large branches (generally considered poor practice); also, removing upright shoots to maintain a tree at its desired height. Compare with heading cut.

watersprout. Vigorous upright shoot that arises from a latent or adventitious bud on older wood. 


\section{FOR MORE INFORMATION}

You'll find more information in the following ANR sources:

California Master Gardener Handbook. Publication 3382, 2002.

Fruit Trees: Pruning Overgrown Trees. Publication 8058, 2002.

Pests of Landscape Trees and Shrubs. Publication 3359, 1994.

Pests of the Garden and Small Farm. 2nd ed. Publication 3332, 1998.

Pruning Fruit Trees. Video V85-A, 1985.

Training Young Walnut Trees by the Modified Central-Leader System. Publication 2471, 1982.

See also:

Brickell, C., and D. Joyce. 1996. Pruning and training: A fully illustrated plant-by-plant manual. New York: DK Publishing.

Harris, R. W. Arboriculture: Integrated management of landscape trees, shrubs, and vines. 3rd ed. Englewood Cliffs, NJ: Prentice-Hall, 1999.

Funding for this publication was made possible through a grant from the Elvenia J. Slosson Fund.

Visit our online catalog at http://anrcatalog.ucdavis.edu.You can also place orders by mail, phone, or FAX, or request a printed catalog of products from

University of California

Agriculture and Natural Resources

Communication Services

6701 San Pablo Avenue, 2nd Floor

Oakland, California 94608-1239

Telephone: (800) 994-8849 or (510) 642-2431, FAX: (510) 643-5470

E-mail inquiries: danrcs@ucdavis.edu

An electronic version of this publication is available on the ANR Communication Services Web site at http://anrcatalog.ucdavis.edu.

Publication 8057

(c) 2002 by the Regents of the University of California, Division of Agriculture and Natural Resources. All rights reserved.

The University of California prohibits discrimination against or harassment of any person employed by or seeking employment with the University on the basis of race, color, national origin, religion, sex, physical or mental disability, medical condition (cancer-related or genetic characteristics), ancestry, marital status, age, sexual orientation, citizenship, or status as a covered veteran (special disabled veteran, Vietnam-era veteran or any other veteran who served on active duty during a war or in a campaign or expedition for which a campaign badge has been authorized). University Policy is intended to be consistent with the provisions of applicable State and Federal laws.

Inquiries regarding the University's nondiscrimination policies may be directed to the Affirmative Action/Staff Personnel Services Director, University of California, Agriculture and Natural Resources, 300 Lakeside Drive, 6th Floor, Oakland, CA 94612-3550 (510) 987-0096. For a free catalog of other products, call (800) 994-8849. For help downloading this publication, call (530) 754-5112.

pr-12/02-SB/CR

ISBN 978-1-60107-235-1

This publication has been anonymously peer reviewed for technical accuracy by University of California scientists and other qualified professionals. This review process was managed by the ANR Associate Editor for Pomology, Viticulture, and Subtropical Horticulture. 